\title{
“ALABARDAS, ALABARDAS, ESPINGARDAS, ESPINGARDAS”, O ROMANCE INACABADO DE JOSÉ SARAMAGO.
}

Bianca Rosina Mattia ${ }^{1}$

Afinal, talvez ainda vá escrever outro livro.

(José Saramago, 2009)

Publicado em 2014 pela Porto Editora (Portugal), o último romance do escritor português, Nobel de Literatura de 1998, José Saramago, tem como título um verso extraído da tragicomédia Exortação da Guerra, de Gil Vicente: Alabardas, alabardas, Espingardas, espingardas. A escolha foi inicialmente pensada para ser a epígrafe do livro, uma vez que, ao cogitar a hipótese de escrever outro livro, em 2009, depois de ter finalizado Caim, Saramago propunha chamá-lo de "Belona', que é o nome da deusa romana da guerra." (SARAMAGO,2014 [2009]). Contudo, desta primeira escolha, ainda passou por Produtos Belona $S$. $A$. até decidir pelo título definitivo.

A edição do livro apresenta-se de maneira peculiar ao público leitor. Isso porque, além de trazer o romance inacabado, em seus únicos três capítulos, há as Notas do caderno de José Saramago, referentes ao tempo em que trabalhou no romance, bem como dois textos, em posfácio, escritos umpor Fernando Gómez Aguilera e outro por Roberto Saviano. As ilustrações do livro são de Günter Grass.

Se seguirmos a ordem do sumário, que consta logo no início, nas primeiras setenta e sete páginas, temos a última história que Saramago nos quis contar. Trata-se de um romance que, mesmo sem ponto final, deixou sua mensagem de, nas palavras do editor português Manuel Alberto Valente (2014, p. 37), "manifesto pela paz”.

A inspiração para Alabardas, como conta Saramago em seu diário, nasceu de uma antiga inquietação: "(porquê nunca houve uma greve numa fábrica de armamento) [...]" (SARAMAGO, 2014 [2009], p. 79). E o arranque para a história, ainda conforme o autor, refere-se a uma "bomba que não chegou a explodir na guerra civil de Espanha, como André Malraux conta em L'Espoir’' (2014 [2009], p. 79). Adiante, nas notas de seu caderno, Saramago fará a correção de que tal episódio não consta no livro de Malraux, mas que o teria lido sem recordar a fonte. Contudo, para o objetivo do autor, foi suficiente a

\footnotetext{
${ }^{1}$ Mestranda no Programa de Pós-Graduação em Literatura da Universidade Federal de Santa Catarina. É uma das editoras da Revista Anuário de Literatura. E-mail: biancamattia@gmail.com.
} 


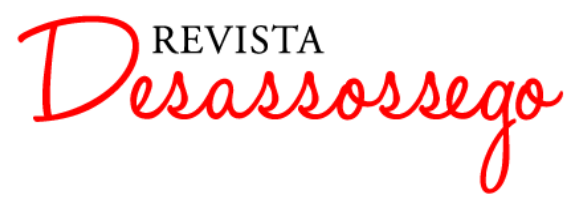

referência feita por Malraux em seu livro “a operários de Milão fuzilados por terem sabotado obuses." (SARAMAGO, 2014 [2009], p. 80).

No primeiro capítulo, já na primeira linha, Saramago apresenta-nos artur paz semedo", homem que "trabalha há quase vinte anos nos serviços de faturação de armamento ligeiro e munições de uma histórica fábrica de armamento conhecida pela razão social de produções belona s. a. [...]" (SARAMAGO, 2014, p. 11). artur não "é nem solteiro, nem casado, nem divorciado, nem viúvo, está simplesmente separado da mulher, [...]" (SARAMAGO, 2014, p. 12). A mulher chama-se felícia, "militante pacifista convicta" que "acabou por não suportar mais tempo ver-se ligada pelos laços da obrigada convivência doméstica e do dever conjugal a um faturador de uma empresa produtora de armas. Questão de coerência, simplesmente, [...].” (SARAMAGO, 2014, p. 12). Ainda neste capítulo, Saramago descreverá artur paz semedo e seu prazer, nervosismo e fortes emoções diante do espetáculo bélico, porém, paz semedo “jamais disparou um tiro, não é sequer caçador de fim de semana, e o exército, perante as suas evidentes carências físicas, não o quis nas fileiras." (SARAMAGO, 2014, p. 14).

E foi no cinema que artur paz semedo assistiu ao L'espoir, de André Malraux "e decidiu que era sua obrigação de apreciador de filmes bélicos e empregado de produções belona s. a. ler um livro que precisamente tratava de uma guerra." (SARAMAGO, 2014, p. 19). A semente para "as vias da tal história "humana"” (SARAMAGO, 2014 [2009], p. 81) estava plantada. O primeiro capítulo encerra após a conversa ao telefone de artur com felícia, onde ele lhe conta sobre o filme e o livro, ao que ela deixará a sugestão para que ele investigue nos arquivos da fábrica durante os anos da guerra civil espanhola. Deste capítulo findo, Saramago revela a frase final do romance - a qual ficou apenas nas notas do seu caderno -“O livro terminará com um sonoro 'Vai à merda', proferido por ela. Um remate exemplar." (SARAMAGO, 2014 [2009], p. 81).

No segundo capítulo, passa-se ao ambiente da fábrica, aos afazeres de artur paz semedo no seu ofício, mas, sobretudo, à sua conversa com o administrador-delegado acerca da possibilidade de trabalhar nos arquivos da fábrica - "Analisar o nosso antigo sistema contabilístico, por exemplo, dos anos trinta, em comparação com o que utilizamos atualmente, [...]" (SARAMAGO, 2014, p. 37) -, como lhe havia instigado felícia. Depois de uma recusa, o administrador-delegado torna a chamar artur paz semedo para the dizer que

2Optamos, para este trabalho, manter a grafia usada pelo escritor português quanto ao registro nos substantivos próprios. 
"talvez fosse interessante fazer umas buscas no arquivo, [...] (SARAMAGO, 2014, p. 46). Por fim, sem ser o fim, no terceiro capítulo, Saramago avança ainda mais nas suas constantes demonstrações da condição humana, por meio de suas personagens. Aqui, artur paz semedo assumirá a nova tarefa frente aos arquivos da fábrica, onde lá estão “os encarregados do arquivo, um já de certa idade, que mais adiante se apresentará como arsênio, outro bastante mais novo, cuja graça é sesinando, superior na escala o primeiro, subordinado o segundo.” (SARAMAGO, 2014, p. 54-55).

Em Alabardas, Saramago não abandona o estilo que lhe é próprio, com a narrativa baseada na oralidade, e que foi inaugurado com a publicação de Levantado do Chão. Para o autor, "se usasse constantemente sinais gráficos de pontuação, seria como se estivesse a introduzir obstáculos ao livre fluir desse grande rio que é a linguagem do romance, como se estivesse a travar o seu curso." (SARAMAGO, 2010 [1982], p. 229). Contudo, o autor de Memorial do Convento, talvez tenha inovado no que se refere aos nomes das personagens. Desta vez, artur paz semedo, felícia, arsênio e sesinando, não são apenas nomes, mas carregam em si despertares e desassossegos imbricados na própria história e transferidos ao/à leitor/a.

"Sairá ao público no ano que vem se a vida não me falta." (SARAMAGO, 2014 [2009], p. 81). Registrou Saramago em seu caderno no dia 24 de outubro de 2009, dia em que também escreveu que já havia corrigido os três primeiros capítulos de Alabardas. As anotações do autor, publicadas em conjunto com o romance inacabado, deixam o livro mais afetuoso especialmente para o seu público fiel. Hábito do autor, a escrita diária, que foi objeto na década de 1990 das publicações de Cadernos de Lanz̧arote, deixou alguns traços, marcas de como foi se desenvolvendo a construção do enredo, ideias para o continuar da escrita, mas com a advertência de que essas "aparecem quando são necessárias." (SARAMAGO, 2014 [2010], p. 83).

Para finalizar, a edição portuguesa apresenta o texto Um livro inacabado, uma vontade firme, escrito pelo espanhol Fernando Gómez Aguilera, autor da cronobiografia "José Saramago: A consistência dos sonhos", publicada em 2008, pela Editorial Caminho (Portugal), bem como responsável pela organização e seleção de "As palavras de Saramago: catálogo de reflexões pessoais. Literárias e políticas", publicado em 2010, pela Companhia das Letras, aqui no Brasil. O texto de Aguilera ultrapassa o limite do relato de como foi o trabalho de Saramago em Alabardas; mistura sentimento e emoção por parte de quem escreve, sobretudo por ter concluído que neste romance, inacabado, temos "um Saramago 


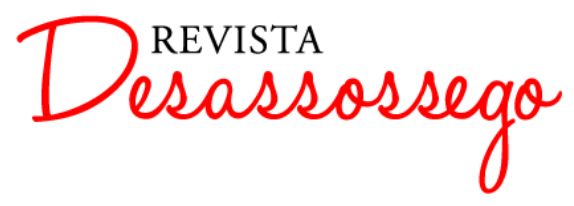

DESASSOSSEGO 15 | JUN/2016 | ISSN 2175-3180

DOI: http://dx.doi.org/10.11606/issn.2175-3180.v8i15p206-210

em estado puro até a última das suas letras, incluindo aquelas que não puderam ser escritas no lugar a que a vontade as tinha destinado, mas que, contudo, ainda hoje ecoam da liberdade da sua poderosa consciência incómoda, insubstituível.” (AGUILERA, 2014, p. 106).

Por sua vez, o jornalista e escritor italiano Roberto Saviano, desassossega ainda mais o/a leitor/a com seu texto Também eu conbeci Artur Paz Semedo. Ao dizer que as "novas páginas de Saramago são o criptograma do sussurro contínuo das revelações misteriosas que recebemos." (SAVIANO, 2014, p. 107), Saviano irá pluralizar artur paz semedo no relato que fará sobre Martin Woods, Tim Lopes, os jornalistas Rodolfo Rincón Taracena, Valentin Valdés Espinosa, Luis Horacio Nájera e Alfredo Corchado, do semanário de Tijuana, Zeta, Bladimir Antuna García, Friedhelm e Cristian Poveda. Neles, Saviano vê as revelações que viu em artur paz semedo, as revelações "de todos os homens e mulheres que se protegeram da idiotice ao perceber que compreenderam os dois caminhos, deixar-se estar a aguentar a vida, a cavaquear com ironia, a tentar juntar algum dinheiro e alguma família e ficar por ali, ou outra coisa. [...] Outro percurso.” (SAVIANO, 2014, p. 108-109).

As ilustrações de Günter Grass, autor alemão, Nobel de Literatura de 1999, permeiam as páginas do livro. São canhões, soldados, fumaça, mas são também uma criança diante disso e um casal lado a lado frente a uma porta aberta, enfim, as ilustrações, junto com os textos em posfácio, para usar as palavras de Pilar Del Río, "reconfortam o leitor, que não sentirá tanto o desalento do final da obra de José Saramago porque outros lhe suavizam a despedida e acentuam o humaníssimo milagre da solidariedade, do companheirismo e da inteligência." (RÍO, 2014, p. 4).

Em abril de 1998, Saramago disse que "se o escritor tem algum papel, é o de incomodar." (SARAMAGO, 2010 [1998], p. 348). Em Alabardas, mais uma vez, incomodou-nos e foi além, deixou-nos em estado de incômodo diante de uma história que, para além de inacabada, é completa na mensagem que por último desejou escrever. O romance inacabado de José Saramago, na sua completude de romance, diário, ilustrações e ensaios, parece mesmo evidenciar, a cada nova leitura que dele se faça, o humanista que se fez escritor. 


\section{Referências}

AGUILERA, Fernando Gómez. "Um livro inacabado, uma vontade firme." Tradução de Helena Pitta. In: SARAMAGO, José. Alabardas, alabardas, espingardas, espingardas. Porto: Porto Editora, Lda, 2014.

SARAMAGO, José. Alabardas, alabardas, espingardas, espingardas. Porto: Porto Editora, Lda, 2014.

As palavras de Saramago: catálogo de reflexões pessoais, literárias e políticas. Seleção e Organização de Fernando Gómez Aguilera. São Paulo: Companhia das Letras, 2010.

SAVIANO, Roberto. "Também eu conheci Artur Paz Semedo." Tradução de Regina Valente. In: SARAMAGO, José. Alabardas, alabardas, espingardas, espingardas. Porto: Porto Editora, Lda, 2014.

VALENTE, Manuel Alberto. “As palavras dos editores.” In: Blimunda, número 28. Lisboa: Fundação José Saramago, setembro de 2014. Disponível em: http://www.josesaramago.org/wpcontent/uploads/2014/09/blimunda_28_setembro_201 4_1.pdf. Acesso em: 23 mar. 2016.

RÍO, Pilar del. "Nós somos o outro do outro.” In: Blimunda, número 28. Lisboa: Fundação José Saramago, setembro de 2014. Disponível em: http://www.josesaramago.org/wpcontent/uploads/2014/09/blimunda_28_setembro_2014_1.pdf. Acesso em: 23 mar. 2016. 